\title{
A Field Method for the Cephalometric X-ray Study of Skulls in Early Nubian Cemeteries ${ }^{1,2}$
}

\author{
JAMES E. HARRIS ${ }^{3}$, DUANE BURNOR, SAMIR LOUTFY, \\ AND PAUL PONITZ \\ University of Michigan, Ann Arbor, Michigan
}

\begin{abstract}
The cephalometer, a clinical and research instrument employed by the orthodontic profession to record standardized x-rays of the human skull, has been modified for research work in remote areas where the usual laboratory facilities are not available. This cephalometer was specifically designed to record cephalograms (head radiographs) on the living Nubian population and their extensive skeletal record. The cephalometer consists of a light, portable tripod stand and an aluminum beam to which is attached at one end a Wehmer cephalostat (head holder), and on the other end an isotope radiation source. Hence, the radiation source and the cephalostat were held in the standard relationship of five feet from source to the mid-saggittal plane of the cranium. Ytterbium-169, with a half life of 32.5 days, was used to expose the film. The isotope and the use of the new Experimental Polaroid X-ray Film permitted the x-ray examination of Nubian skulls with no conventional power source or darkroom facilities.
\end{abstract}

The University of Michigan School of Dentistry has long been interested in craniofacial variation, growth abnormalities, and growth prediction. Hence, the University has conducted long-term cephalometric and dental studies of the growth of normal school children, clinical patients and children with congenital malformation. These studies have been supplemented by an extensive experimental laboratory approach.

It was, then, with special interest that an opportunity to examine the long skeletal history of the past and present Nubian populations of southern Egypt was explored. This project was made possible by invitations extended by Mr. Nickolas Millet of the American Research Center in Egypt, Inc. and Dr. Robert Adams and Dr. Keith Seele of the Oriental Institute of the University of Chicago to examine their skeletal material previously excavated from cemeteries located at Gebel Adda, Ballana, Qustul, Adindan, and Kasr E1 Wizz. All of these sites are located in Egyptian Nubia between Abu Simbel Temple and the Sudanese border. Therefore, an expedition under the direction of Dr. James E. Harris of the School of Dentistry at the University of Michigan was launched during the spring of 1965 to examine the dental problems and cranio- facial variability of the ancient Nubians living at these sites.

The cemeteries investigated provided well-preserved skeletal material from the C-Group, Meroitic, X-Group, Christian, and Moslem archaeological periods, and they ranged in time from approximately 2,000 B.C. to 1,800 A.D. Material from the Archaic and New Kingdom periods was unavailable due to the previous inundation by the Nile, which raised the water level about six meters, but material from these periods will be $x$-rayed during the spring of 1966 in the Egyptian Museum in Cairo.

The availability of the present Nubian population recently relocated in the Kom Ombo area of Upper Egypt, together with this continuous past skeletal record, offer a unique opportunity to observe the craniofacial variation over an extensive period of time (approximately 4000 years). Our insight into the craniofacial variability of

\footnotetext{
1 Sponsored by the University of Michigan and the University of Alexandria.

2 Supported by the United States Public Health Service, National Institutes of Health grant 5X2511 Public Health Service Research grant 1 SO1 FR-5321-04 from the General Research Support Branch, Division of Research Facilities and Resources, and assisted by of Research Facitities and Res a grant from the Faculty Research Fund of the Horace H. Rackham School of Graduate Studies of the University of Michigan.

3 Assistant Professor of Dentistry, University of Michigan, Ann Arbor, Michigan.
} 
the modern Nubians is enhanced by this skeletal record.

Gebel Adda, the site of the expedition headquarters, is located on the eastern bank of the Nile about four miles south of Abu Simbel Temple. Electrical power and satisfactory laboratory space were lacking. In addition, $120^{\circ}$ temperatures and the fine sand constantly in suspension in the atmosphere quickly render most machinery useless. Therefore, it was necessary to construct a simple, rugged and easily transportable cephalometer that was independent of a conventional power source.

The skeletal material in Egyptian Nubia could not be removed to the University for study and it was of interest to investigate the living population. Cephalometrics seemed to offer the most efficient method of collecting permanent records for the following reasons:

1. Cephalograms provide a permanent collection of measurable, reproducible, two-dimensional radiographs. A set of lateral, PA, and basal cephalograms on each skull permits a three-dimensional interpretation.

2. The analysis of the cephalogram may be conducted at the University at relative leisure rather than in the field. This permits computer analysis while analyzing the cephalograms and hence modification of the statistical observation at any time.

3. The cephalogram is independent of a preconceived set of observations and may be re-evaluated by any observer at any time.

4. The cephalogram permits comparison with other populations now recorded by this technique, i.e., United States, Denmark, Sweden, Australia.

5. This technique permits re-evaluation of the living Nubian population at any given time in the future.

\section{DESCRIPTION OF EQUIPMENT}

Basically, a cephalometer consists of a source of radiation held at a fixed distance from a head-holding device to which a film cassette holder is attached. In this instance, the distance from the source to the midsaggital plane of the skull was five feet, and the distance from the mid- sagittal plane to the film plane was 18 $\mathrm{cm}$. Although there are many commercial cephalometers available on the market today, they are designed for permanent installation. Hence, the proposed cephalometer was designed to incorporate those elements, such as the cephalostat, ${ }^{4}$ which were manufactured and proven in the clinic and teaching institutions. The remainder of the cephalometer was fabricated by the Viso Corporation for portability and dependability.

The cephalometer may be discussed in terms of three components, i.e., the stand, the head-holder or cephalostat, and the source of radiation (fig. 1).

\section{The stand}

The stand or framework has two purposes: (1) It must provide adequate but adjustable support for a rigid beam which maintains the radiation source in an absolute fixed position in relation to the cephalostat and the film holder. Since this equipment was to be used for both living populations and skeletal material, the framework was designed to hold the beam in a vertical or horizontal position (figs. 1 and 2). The vertical position permitted the cephalometric examination of a well-preserved, desiccated body without removing the head. The horizontal position of the beam allowed cephalometric examination of living people standing or comfortably seated in an adjustable chair. (2) It must include a rigid beam (extruded aluminum was used in this instrument) which relates the other two major components of the cephalometer, that is, the radiation source to the cephalostat and the film holder. In fact, the precision of attachment of the various components to this beam and its rigidity are the critical attributes of any cephalometer. For example, in the lateral cephalogram the central beam of the x-ray must pass through the ear rods of the cephalostat perpendicular to the film holder. Otherwise, vast distortion and experimental error will be incurred.

The stand is composed essentially of a heavy duty commercially available photographic tripod to which the rigid beam

\footnotetext{
4 Standard Wehmer Headholder manufactured for general use in the orthodontic office or clinic.
} 


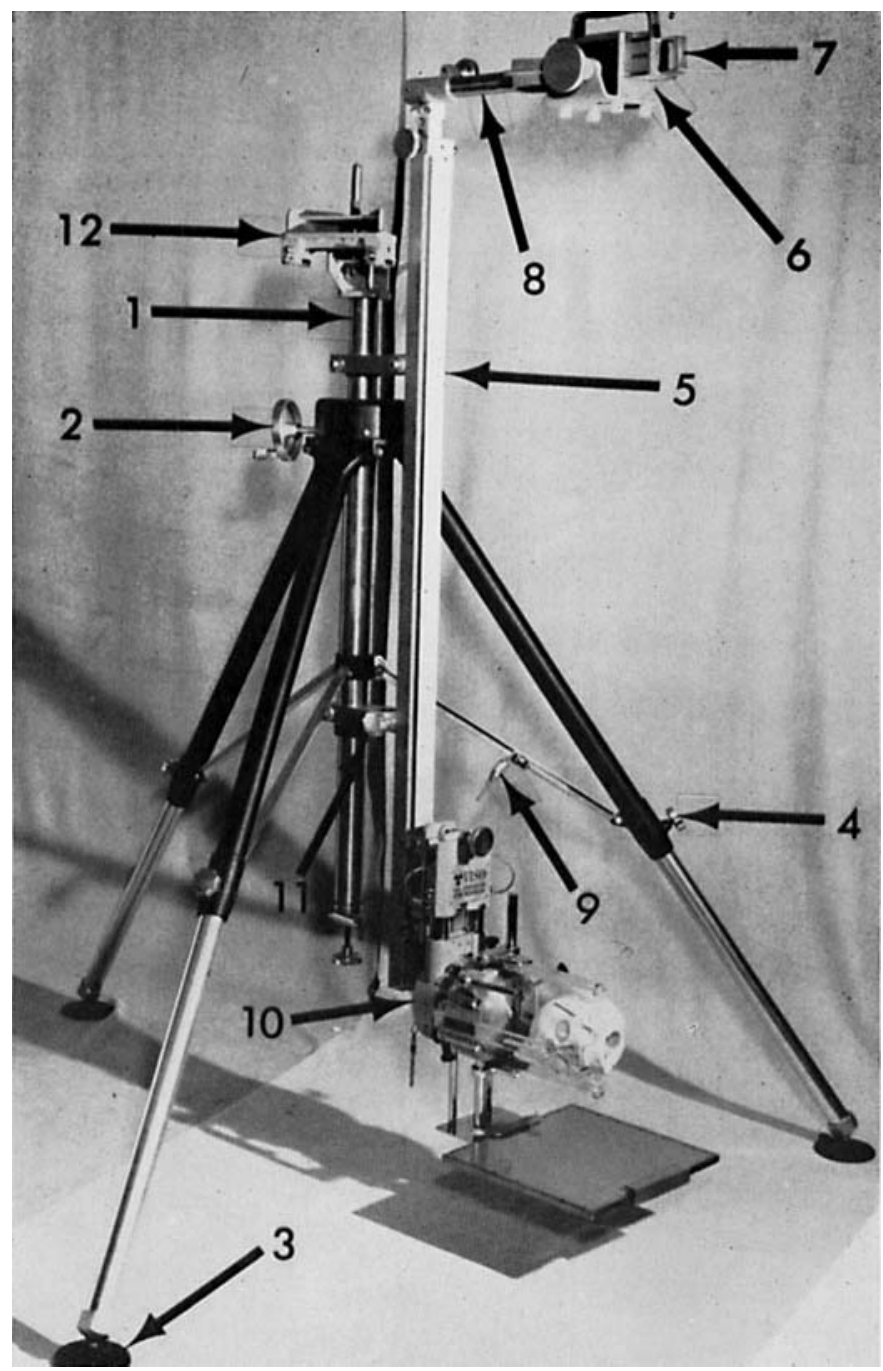

Fig. 1 The complete cephalometric apparatus.

1. Supporting post with toothed rack

2. Elevating wheel

3. Universal foot

4. Adjustable leg lock

5. Pivoted aluminum beam

6. Viso Exposure Unit

and other parts of the cephalometer were attached. The beam attached to a center pole could be raised and lowered with a geared wheel and locked into any position. The legs were fully adjustable for use on any type of floor. The tripod and the supporting beam were folded together and fitted into a canvas bag for easy handl-
7. Shutter

8. Removable extension arm

9. Universal hexagonal wrench

10. Cephalostat

11. Adjustable elevation stop

12. Horizontal beam holder

ing and transportation by one person, since the total weight was 45 pounds.

\section{The cephalostat}

The cephalostat is a standard Wehmer headholder designed for use in the private Orthodontic office (fig. 2). It was selected because of its present use at the Univer- 


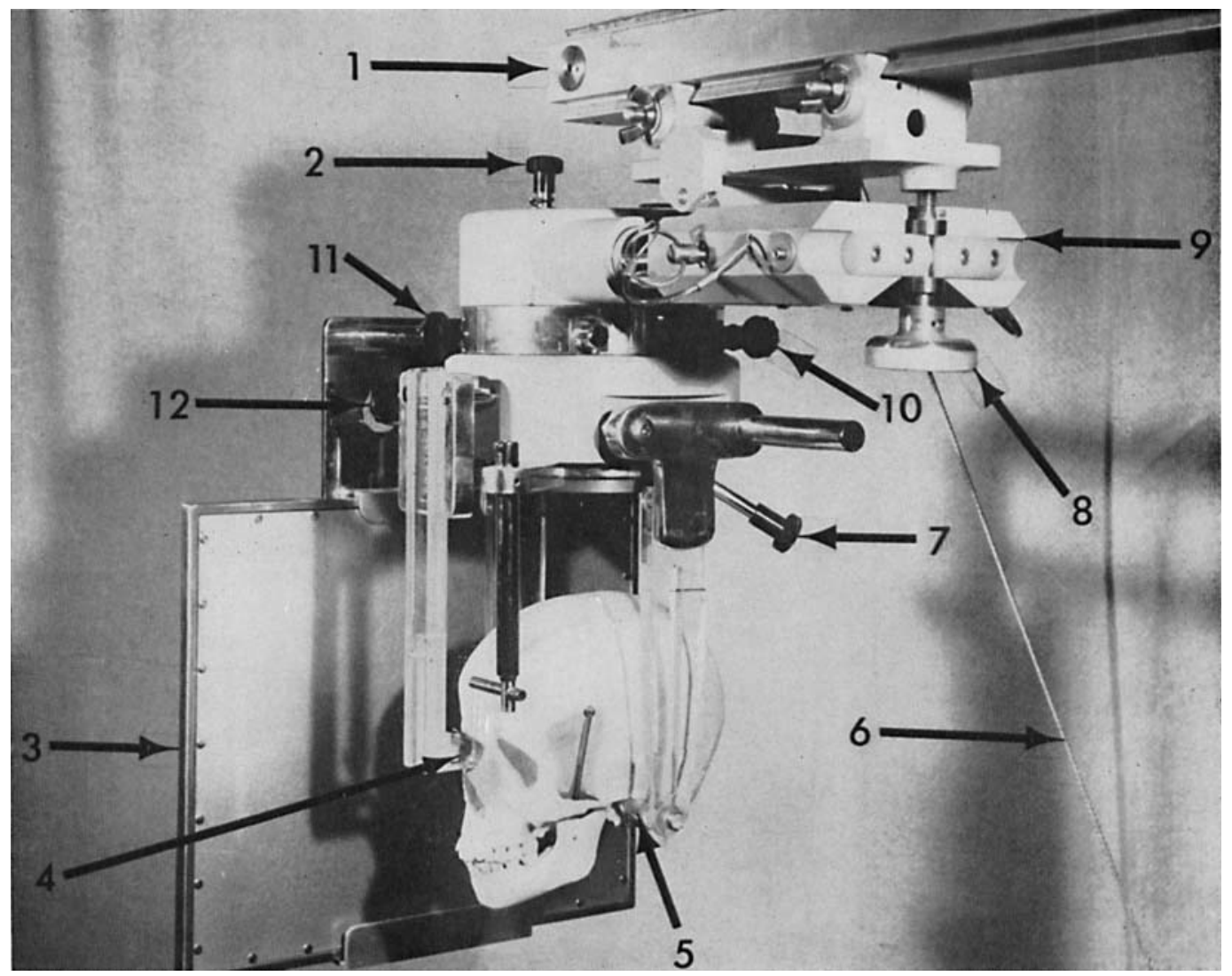

Fig. 2 Wehmer cephalostat and film holder.
1. Pivoted aluminum beam
2. Pivot lock
3. $10 \times 12$ inch Phillips magnesium film cassette
4. Anterior nasal head positioner
5. Ear rod
6. Beam stabilizing guy wire

sity of Michigan Elementary School, where it had proven its durability and flexibility. While being relatively light and compact, this headholder permits the operator to take lateral, oblique, or PA cephalograms rapidly.

The Wehmer cephalostat has attached to it a film cassette holder which is calibrated in millimeters and adjustable so that the film-subject distance can be readily determined. The cephalostat is attached to the rigid beam of the cephalometer by a machined holding device with an adjustable screw that permits exact alignment of the ear rods with the central
7. Ear rod adjusting lever

8. Cephalostat alignment screw

9. Cephalostat beam holder

10. Film holder stop

11. Film holder adjusting lock

12. Lock for anterior nasal head positioner

beam of the x-ray source. The cephalostat has its own felt-lined carrying case and all together weighed thirty and onefourth pounds.

\section{The radiation source}

An Ytterbium-169 isotope in an appropriately shielded container with a simple manually-operated shutter ${ }^{5}$ was used as the source of radiation.

Ytterbium-169 is a radioactive isotope with a half-life of 32.5 days, with a high intensity of radiation observable at $52 \mathrm{KEV}$ (fig. 4). Although the emitted radiations

\footnotetext{
5Viso Model 601 Radiographic Exposure Unit.
} 


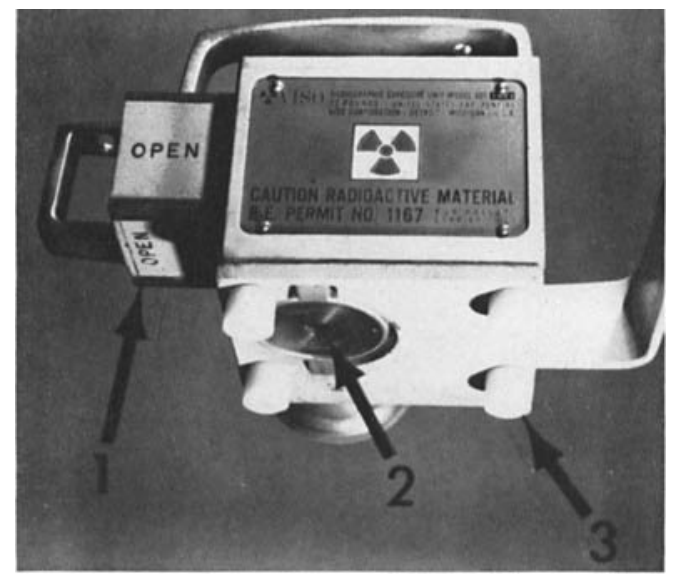

Fig. 3 Radiation source.

1. Shutter

2. Beam columnating gate

3. Plastic mounting nuts

are in a desirable range, exposure times were observed to be too long for living tissue. Hence, present plans are that an auxillary portable $90 \mathrm{KV}$ x-ray head will be used when sampling the living population. The Ytterbium-169 was contained in a sealed aluminum holder. The radioactive pellet was of two millimeter crosssectional diameter to give an approximate point source of radiation. A tungsten diaphragm was placed over the shutter to yield a collimated beam that was only slightly over $40 \mathrm{~cm}$ in diameter at the target-film distance. In the expedition to Egypt, 70 Curies of YB-169 were used because the half-life of 32.5 days and the subsequent decay necessitated an everincreasing exposure time (from April 1, 1965 until May 15, 1965, the exposure time increased from 30 to 70 seconds). Although the long exposure time of this radiation source was a disadvantage, the high contrast in the resulting cephalograms and the reliability under difficult circumstances were of far greater advantage. The YB-169 source and container were placed in a protective box, the total weighing 26 pounds.

\section{Recording medium}

Two recording systems were used to visualize the radiographic information produced by the cephalometer:

1 . Wet process radiography.

2. Polaroid self-developing (or rapid) radiography.

Wet process radiography used $10 \times 12$ lightweight cassettes equipped with high speed DuPont screens to expose Kodak Blue Brand film. Processing of wet process film was accomplished in a conventional lightweight stainless steel tank. A standard developer and fixer and film hangers were used to process and wash the film. All developed, but unprocessed film

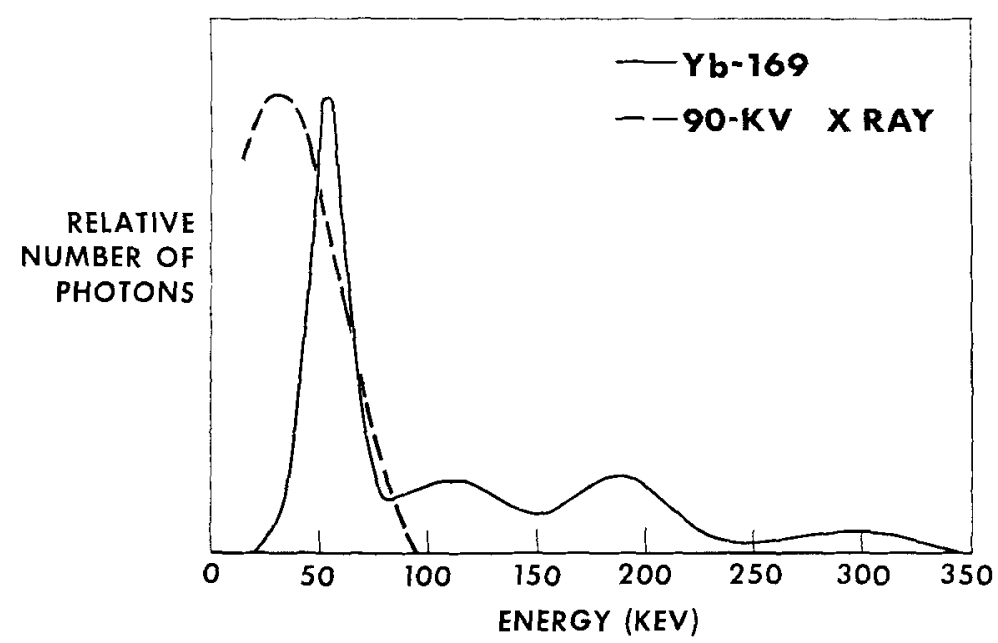

Fig. 4 Comparison between the Yb-169 isotope and a conventional $90 \mathrm{KV}$ X-ray source. 


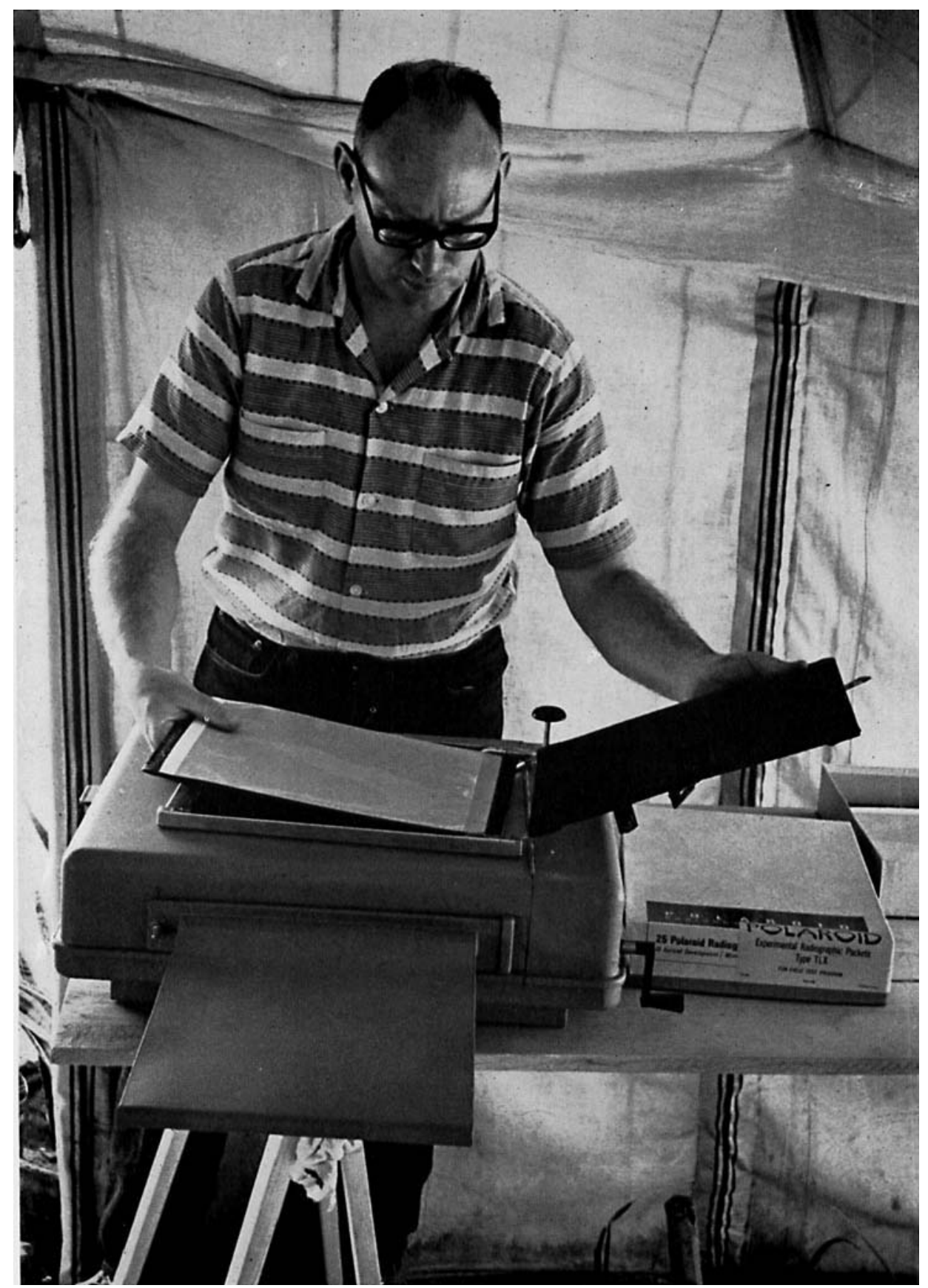

Fig. 5 Portable spring loaded experimental Polaroid Radiographic film processor. 
was stored in a light-tight box at the end of each day.

A darkroom was made out of a stateroom on the houseboat used by the expedition for a living facility.

Polaroid self-developing (or rapid) radiography. An experimental model, portable, non-electric, daylight-operating Polaroid Rapid Radiographic Processor was designed by the Polaroid X-Ray Research Engineering Department. This unit utilized a cassette which could also be loaded in daylight. After exposure, the cassette was placed in the Polaroid Radiographic Processor where the film was processed in 45 seconds. The processing was accomplished without the use of electricity, a darkroom, running water, washing or drying film. Each radiographic packet was complete with a negative, positive image sheet, and its own developing reagent contained in a sealed container. During the processing cycle, the developing reagent was spread with a controlled miniscus between the negative and positive sheets.

Polaroid X-Ray Technical Services made available an experimental film for the expedition. (Polaroid TLX radiographic packets.) This film packet resulted in a positive image on a polyester base receiving sheet. Radiographs on this film can be visualized by reflected light, as well as transmitted light. Polaroid TLX film required one-third the radiation exposure that was used with the wet process film technique.

Radiation protection. A flexible, leaded sheet was used to construct a simple but

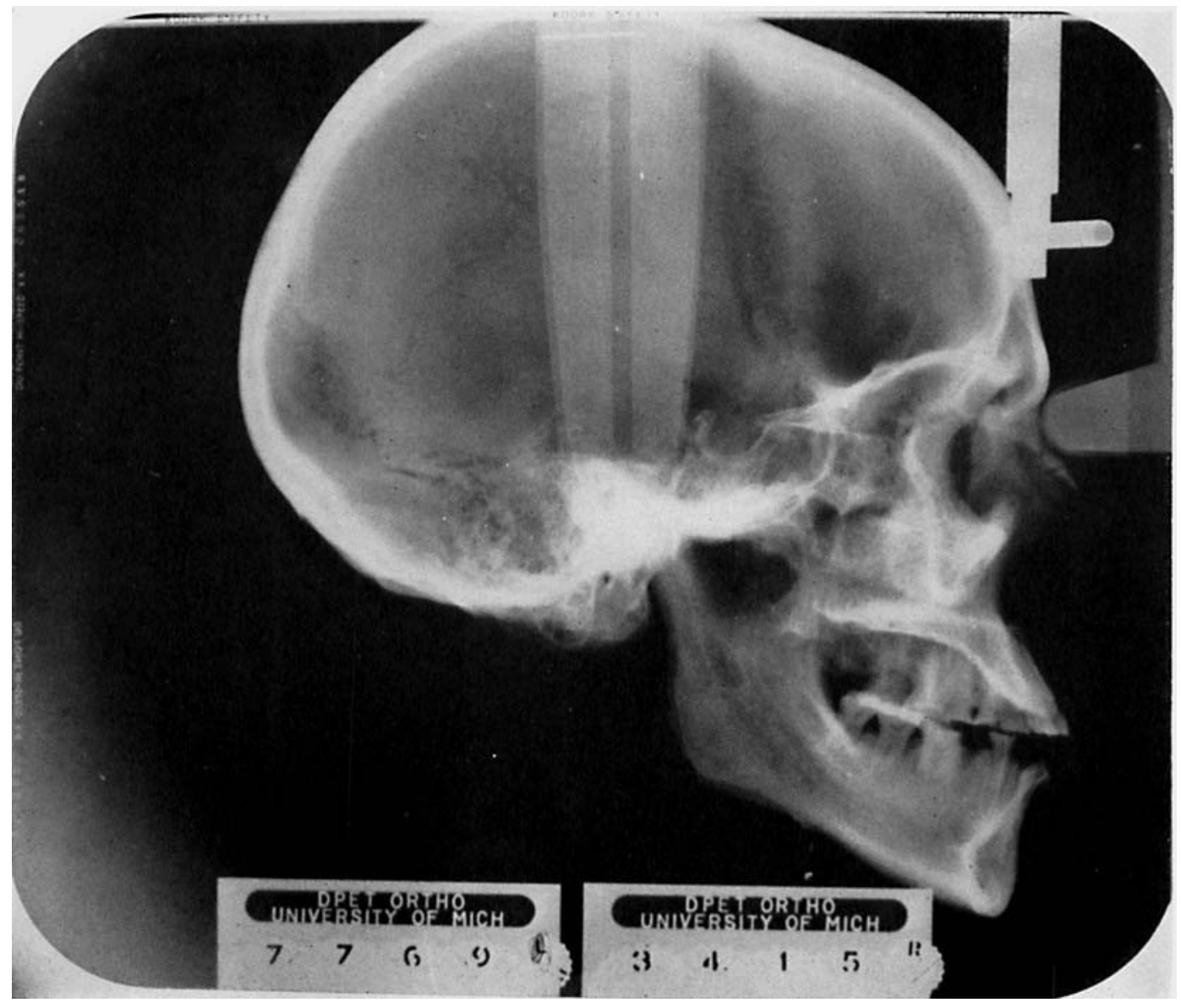

Fig. 6 Lateral cephalogram from conventional wet process radiograph. 
effective radiation shield for the protection of individuals near the cephalometer.

\section{SPECIAL CONSIDERATIONS OF TECHINIQUE MODIFICATION DUE TO THE EXPEDITION INTO NUBIA}

The cephalometer and the supporting equipment were developed for use anywhere in the field, specifically where no utilities are available. The first expedition into Nubia presented several problems.

Perhaps the greatest stress on both the equipment and the personnel was the heat. The temperature in the work tent where the cephalometer was housed ranged between $60^{\circ}$ Fahrenheit in the evening, to $120^{\circ}$ Fahrenheit in the afternoon. At the higher temperature, the heat from radiation would cause the film in the wet process to fog.

The yield of the Polaroid radiographic film packets has been calculated at about $80 \%$. This compared favorably to the wet process film results.

Each recording system had its share of problems due to the extreme field conditions. The wet process system required 4 to 5 hours a day of loading, unloading,

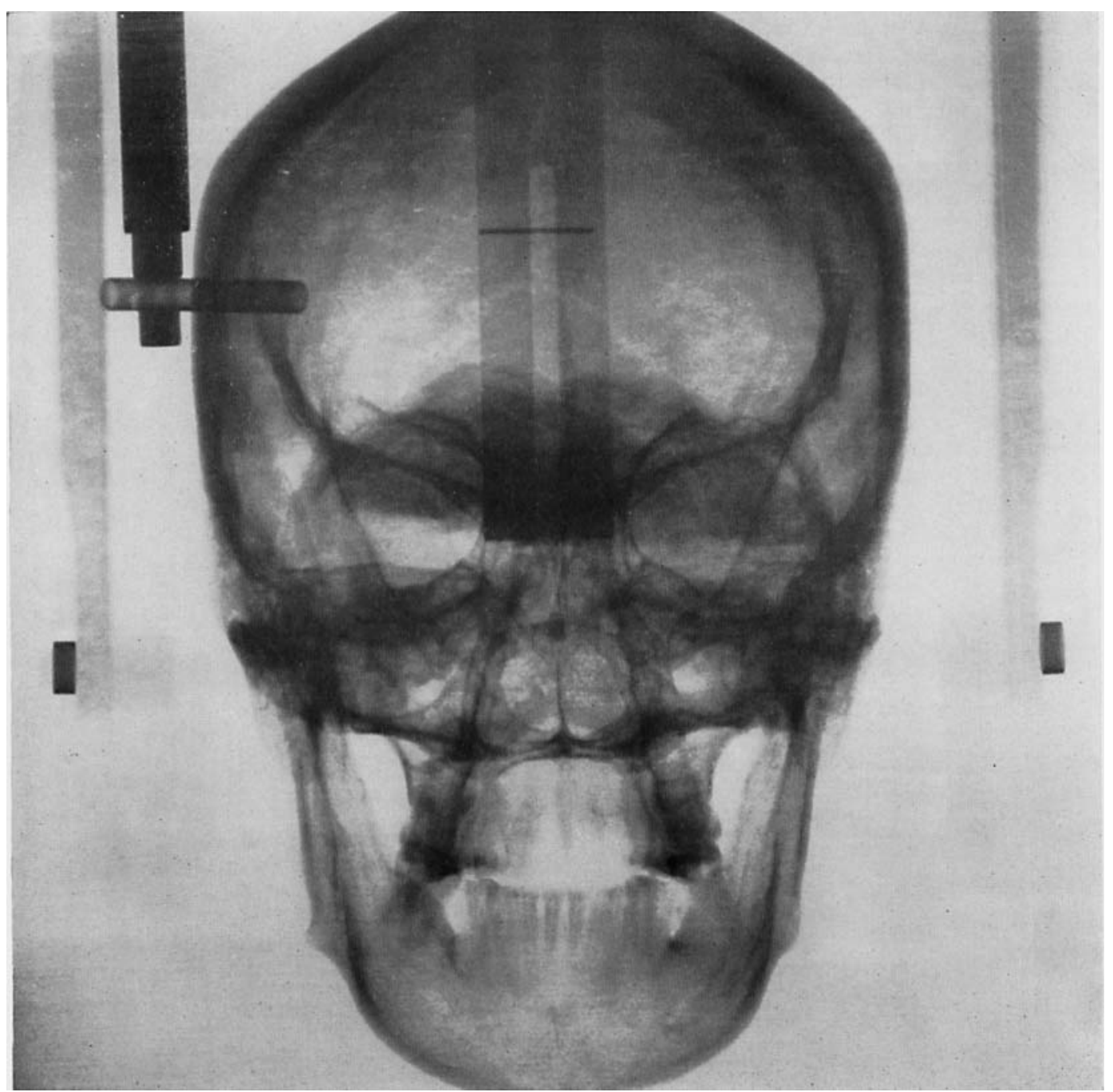

Fig. 7 PA (posterior-anterior) cephalogram from Polaroid TLX Radiographic packets. 
developing, fixing, washing and drying. A number of these films were lost due to heat, fog, poor water and difficult drying conditions. The intense heat affected the Polaroid Radiographic Process by reducing the developer layer thickness during the processing cycle. The roller pressure on the experimental processing equipment was not easily adjustable as the temperature climbed each day. (Modifications have since been made to eliminate this problem.) Thinner developer layer thickness resulted in difficult separation of the positive and negative elements of the film packet.

The Polaroid Radiographic Process was also used to stabilize and correct the radiation focus of the cephalometric equipment whenever it was moved.

Fortunately, the temperature of the water of the Nile remained constant at $75^{\circ}$ Fahrenheit, which permitted constancy in the developing of the conventional Kodak film.

Fine sand and dust, because of the extremely dry conditions and the frequent winds, permeated all the equipment. Extreme care was taken in protecting all moving parts on the cephalometer from the sand. Nevertheless, it eventually caused the Wehmer cephalostat to jam, as well as the experimental Polaroid Radiographic Processor, both precision-machined equipment. Undoubtedly, in an expedition requiring many months in the desert, the sand would produce the greatest hazard to maintenance of equipment and quality control. ${ }^{6}$

The intensity of the direct sun, with the great reflection of light from both the sand and the Nile forced extraordinary care in the handling of film. Even a cassette, normally light-tight in an institutional building in the United States, proved to be vulnerable to light leaks in the work areas of Nubia.

Finally, the water of the Nile, with a heavy concentration of sediment and occasional oil slick from passing steamers, was used in mixing all of the fixer and developer and in washing the conventional film. The fixer and developer were mixed from dry powder brought to Nubia to save weight, and for convenience in handling, and were mixed to fill one-gallon containers. Under these circumstances, approximately $75(10 \times 12)$ films could be developed and fixed before changing solutions. All film was developed at three and one-half minutes, fixed for five minutes and washed for five minutes. Because of the limitation of eight cassettes and 12 hangers, film was stored in a commercially constructed, light-tight box, since the output of the cephalometer was greater than the capacity of the darkroom. The films were hung to dry on a clothesline, using clothespins to secure the cephalograms and, hence, freeing the hangers for more developing. All film had to be rewashed and refixed upon return to the University of Michigan Medical Center.

In the five weeks spent in Nubia at Bebel Adda, approximately 2,500 cephalograms were exposed and developed.

6 The authors wish to express deep appreciation to Polaroid X-Ray Technical Services for their support. Polaroid experimental processors and film packets were made available to determine and evaluate the actual problems of the extreme climatic conditions experienced. 